\title{
Metas de inflação em perspectiva: a influência do trinômio reputação-credibilidade-transparência sobre a economia
}

\author{
GABRIEL CALDAS MONTES*
}

Inflation targets in perspective: the influence of the reputation-credibility-transparency trinomial on economics. Although inflation target regime seeks to serve as a reference for the expectation formation process of the agents, its implementation does not necessarily imply the acquisition or the best result in terms of economic growth. The present article aims the development of a model that explains, by firms' investment decisions, the product path behavior, undertaking monetary authority may present distinct situations associated with the reputation-credibility-transparency trinomial. The article also detaches different kinds of reputation and its degrees.

Keywords: reputation; transparency; inflation target; investment.

JEL Classification: E12; E22; E31; E58.

\section{INTRODUÇÃO}

Atualmente, um número expressivo de países adota o regime de metas para a inflação tanto com o intuito de desinflacionar a economia como para manter e/ ou promover a estabilidade dos preços. Este regime foi implementado, inicialmente, na Nova Zelândia, Reino Unido e Canadá, sendo posteriormente adotado em países como Austrália, Espanha, Finlândia e Suécia. Ao longo dos últimos anos diversos países vêm aderindo ao regime de metas de inflação como uma espécie

\footnotetext{
*Doutorando em Economia e Professor Substituto da Universidade Federal Fluminense (UFF). Endereço Postal: Travessa dos Ourives, $\mathrm{n}^{\circ}$. 55, Vila Progresso; Bairro: Pendotiba; Cidade: Niterói - Rio de Janeiro. E-mail: gabrielmontesuff@yahoo.com.br. Agradeço os profícuos comentários da Professora Carmem A. Feijó e do Professor Helder Ferreira de Mendonça e ao parecerista anônimo desta revista. No entanto, não são responsáveis por falhas e omissões que persistam. Submetido: Setembro 2006; Aprovado: Agosto 2007.
} 
de novo paradigma a ser seguido para a condução da política monetária. O Brasil implementou o regime de metas de inflação em junho de 1999, após a opção pela mudança em seu regime cambial, devido aos sucessivos ataques especulativos que vinham sofrendo os países que adotaram uma estratégia de âncora cambial como forma de combater o processo inflacionário.

Os fundamentos teóricos que justificam a adoção do regime de metas para a inflação se baseiam nos desdobramentos da literatura relacionada ao debate "regras versus discrição". Desdobramentos esses que resultaram também nos argumentos relacionados à importância da reputação, da credibilidade e da transparência da autoridade monetária e suas políticas para economias convivendo com taxas de inflação indesejada. A questão da credibilidade foi apresentada pela primeira vez por Fellner (1976; 1979). Posteriormente, Kydland e Prescott (1977) e também Barro e Gordon (1983a; 1983b) desenvolveram trabalhos acerca da credibilidade da política monetária e da reputação da autoridade monetária analisando suas implicações no que se refere ao problema de inconsistência temporal.

Quanto à questão da transparência, esta tem sido vista como contribuindo para reduzir o nível de incerteza na economia, atenuando a existência de informação assimétrica entre autoridade monetária e demais agentes econômicos. De acordo com Mendonça (2006: 178): "Dado que há o reconhecimento de que a efetividade da condução da política econômica depende de alguma forma da capacidade do público antecipar as ações do banco central, é esperado que a transparência ajude os agentes econômicos a prever melhor as ações da política monetária. Nesse sentido, a transparência contribuiria para o aumento da responsabilidade do banco central no alcance de suas metas anunciadas e, por conseguinte, para o aumento da credibilidade".

De acordo com Svensson (1998: 14), o regime de metas de inflação é caracterizado por: "1) an explicit quantitative inflation target, 2) an operating procedure, inflation-forecast targeting, which uses an internal conditional inflation forecast as an intermediate target variable, 3) a high degree of transparency and accountability". O regime de metas para a inflação busca coordenar as expectativas dos agentes econômicos relacionadas ao comportamento esperado da inflação, evitando, assim, repasses exagerados para a inflação observada. Como conseqüência, ao obter êxito em fazer convergir as expectativas dos agentes para a meta estabeleci$\mathrm{da}$, a autoridade monetária acaba sancionando essas expectativas. ${ }^{1}$

Embora o regime de metas para a inflação busque servir como referência para

\footnotetext{
${ }^{1}$ Svensson (1998: 15) aponta as seguintes dificuldades acerca do regime de metas para a inflação: "The greatest problem with inflation targeting is arguably the central bank's imperfect control of inflation. Inflation control is imperfect due to lags in the transmission mechanism, uncertainty about the transmission mechanism, the current state of the economy and future shocks to the economy, and the influence of other factors than monetary policy on inflation, in particular shocks that occur within the control lag. The imperfect control makes the implementation of inflation targeting hard". Contudo, argumenta que "there is a solution to this formidable problem, namely to use a conditional inflation forecast as an intermediate target variable".
} 
o processo de formação das expectativas de inflação dos agentes, sua implementação não implica necessariamente a obtenção do melhor resultado em termos de crescimento econômico. Caso a autoridade monetária não possua uma reputação adequada e forte e não atue de forma transparente por meio da implementação de políticas críveis, além de encontrar dificuldades em fazer convergir tanto as expectativas para a inflação quanto a inflação observada para a meta de inflação, a manipulação do principal instrumento de política monetária (a taxa básica de juros) implicará maiores custos para a sociedade em termos de produto e de emprego. Em um ambiente onde se verifica um aumento das expectativas de inflação e da inflação observada em relação à meta, a autoridade monetária atuará elevando a taxa básica de juros, encarecendo o crédito, o financiamento e postergando decisões de investimentos, reduzindo potencialmente o nível de atividades. Nesse sentido, a questão que o trabalho irá discutir encontra-se relacionada à trajetória descrita pelas flutuações no produto quando analisadas situações distintas referentes à influência que exerce a reputação, a credibilidade e a transparência da autoridade monetária e suas políticas sobre a economia.

As flutuações no produto, decorrentes das perturbações que se observam e que acabam por afetar o funcionamento da economia, podem ser atribuídas a uma série de impulsos, tais como choques de oferta, choques de política e choques de demanda privada, podendo os dois primeiros ter suas origens no próprio país ou ser transmitidos do exterior por meio das relações comerciais e financeiras.

A visão keynesiana de funcionamento da economia considera que alterações na demanda agregada são capazes de provocar flutuações no emprego e no produto. Os choques de demanda privada são conseqüência, basicamente, de flutuações ocorridas no investimento agregado, pois o investimento agregado é considerado o componente mais volátil da demanda agregada. Sendo assim, variações no investimento implicam alterações no produto por meio da ação do efeito multiplicador, via propensão a consumir da sociedade. De acordo com Romer (2001: 330), “... if we want to understand how such forces as government purchases, technology, and monetary policy affect aggregate output, we must understand how consumption and investment are determined".

Assim, com ênfase nas perturbações provenientes de choques de demanda privada, o consumo e o investimento são identificados como as variáveis importantes para explicar as flutuações que se verificam na economia. Cabe ao investimento explicar os impulsos e ao consumo, o efeito de transmissão dos movimentos oscilatórios do produto e da renda. A origem das flutuações na economia se deve em grande parte às incertezas existentes no processo de tomada de decisões e na formação das expectativas. As incertezas são as responsáveis por provocarem variações nas expectativas que os agentes formam e na confiança que possuem quanto aos rumos futuros que a economia irá tomar. Como a decisão a respeito da escolha de uma carteira de ativos depende dos diferentes graus de liquidez apresentados pelos ativos e da lucratividade futura esperada - sendo essa inerentemente incerta - , conseqüentemente, pelo fato de as expectativas serem voláteis, os investimentos acabaram sendo também. 
O presente trabalho tem como objetivo desenvolver um modelo ${ }^{2}$ que explique, por meio das decisões de investimento de firmas, o comportamento das trajetórias verificadas para o produto assumindo que a autoridade monetária apresenta duas situações distintas relacionadas ao trinômio reputação-credibilidade-transparência. As interações entre a reação das firmas e as situações descritas para as autoridades monetárias irão exercer influências diferentes sobre a capacidade de a autoridade monetária atingir a meta para a inflação, assim como sobre sua capacidade de afetar a performance referente à trajetória de crescimento do produto da economia. O modelo irá mostrar que, sendo a autoridade monetária capaz de afetar as decisões de investimento, por meio da percepção do público a respeito de seus anúncios e da maneira como implementa suas políticas monetárias, ou seja, por meio de um determinado status para o trinômio que traduz essa percepção, em última instância será capaz, também, de promover alterações no produto, no emprego e na renda. $\mathrm{O}$ modelo mostrará assim que em um regime de metas para a inflação, quando a autoridade monetária possui uma reputação consolidada e atua de maneira transparente por meio da implementação de políticas críveis, no que a estabilidade da inflação é alcançada, a autoridade monetária possui graus de liberdade para implementar políticas monetárias que estimulem o lado real da economia.

Além dessa introdução, o artigo encontra-se organizado da seguinte maneira: a seção dois, tendo como referência o trabalho de Fazari-Ferri-Greenberg (2003), apresenta um modelo que busca explicar a evolução do produto ao longo do tempo com base no comportamento da demanda (investimento e consumo); a seção três, com base no comportamento do produto descrito na seção anterior, analisa a influência da reputação, da credibilidade e da transparência (trinômio) da autoridade monetária e suas políticas sobre a economia. Para isso, são destacadas duas situações distintas para o trinômio e duas situações distintas para o tipo de reputação da autoridade monetária, cada uma gerando resultados diferentes para a trajetória de crescimento do produto. A seção aborda também a maneira pela qual a autoridade monetária faz para aumentar sua força reputacional; a seção quatro apresenta o comportamento dinâmico da dívida das firmas e como esse comportamento é afetado com base nas situações distintas que serão apresentadas para o trinômio, o que, por conseguinte, acaba afetando as decisões de investimento das firmas, gerando trajetórias distintas de crescimento do produto; a seção cinco trata das considerações finais com base nos argumentos do texto e conclui apontando as diferenças fundamentais entre a abordagem tradicional acerca do modelo de condução da política monetária sob o regime de metas para a inflação e a abordagem acerca do mesmo tema, sob uma perspectiva pós-keynesiana, à luz do modelo aqui presente.

\footnotetext{
${ }^{2}$ De forma estilizada, com objetivo de simplificar o modelo a ser desenvolvido sem, contudo, comprometer seus resultados, supõe-se uma economia operando sob o regime de câmbio flexível, com metas para a inflação e apresentando orçamento público e contas externas equilibrados.
} 


\section{O MODELO}

Os modelos pós-keynesianos que buscam explicar os motivos que levam o produto e o emprego a oscilarem no curto prazo de modo geral apresentam as seguintes características (Eichner, 1979): (i) atribuem ao investimento papel de destaque pelas flutuações na economia; (ii) levam em consideração as alterações ocorridas na participação no produto desempenhada pelos diferentes agentes (distribuição de renda) quando gastos discricionários são efetuados na economia; (iii) são construídos em bases microeconômicas nas quais assumem que firmas possuem poder suficiente de formar preços acima dos custos marginais, sendo o mark-up ajustado de acordo com a necessidade de gerar internamente os fundos que serão utilizados para a realização dos investimentos; (iv) assumem que o emprego depende principalmente do produto agregado e, este último, da demanda agregada, portanto, alterações no salário nominal irão, na verdade, exercer influência sobre os preços, pois afetam os custos que a firma incorre com trabalhadores e, assim, o seu mark-up; (v) enfatizam a importância da disponibilidade de crédito em permitir que firmas preencham a lacuna entre o nível desejado de gastos discricionários e a liquidez existente (motivo finance), concluindo que a disponibilidade de crédito é importante em determinar não somente os gastos discricionários mas, também, as crises de liquidez que se verificam.

Tendo como referencial teórico o trabalho de Fazzari-Ferri-Greenberg (2003), o modelo destaca o comportamento do investimento como fonte de flutuações da economia, ficando o consumo responsável pelo processo multiplicador.

\section{Investimento}

O comportamento do investimento pode ser descrito por meio da equação (1), em que $I_{t}$ é o nível real de investimento no período $t, Y_{t-1}$ é o produto real no período anterior, $Y_{t}^{e}$ é o produto real esperado em $t$ baseado em informações do período $t-1, P_{t}$ é o nível geral de preço em $t$ e $C F_{t}^{e}$ é o fluxo de caixa nominal esperado no período $t$,

$$
I_{t}=\eta_{0} Y_{t-1}+\eta_{1}\left(Y_{t}^{e}-Y_{t-1}\right)+\eta_{2}\left(\frac{1}{P_{t}}\right) C F_{t}^{e}
$$

Os termos da equação (1) podem ser assim entendidos: o primeiro termo, $\eta_{0} Y_{t-1}$, pode ser interpretado como o investimento associado à reposição do capital que se depreciou (sendo $\eta_{0}=\delta \varphi$, em que $\delta$ é a taxa de depreciação e $\varphi$ a razão capital-produto); o segundo termo, $\eta_{1}\left(Y_{t}^{e}-Y_{t-1}\right)$, tendo como referência o modelo acelerador, indica a influência sobre o investimento das expectativas formadas para o produto (se for verificada uma diferença entre as expectativas formadas em $t$-1 para o produto em $t$ e o produto observado em $t$-1, então o investimento sofrerá uma alteração com base em $\eta_{1}$ ), e o terceiro termo apresenta a influência sobre o investimento em $t$, do fluxo de caixa nominal esperado em $t$ deflacionado pelo 
índice geral de preços em $t$, sendo o parâmetro $\eta_{2}$ responsável por transmitir as variações ocorridas no $C F_{t}^{e}$ sobre o investimento, ou seja, representa a influência sobre o investimento da disponibilidade de fundos gerados para financiá-lo. ${ }^{3}$

Sendo a taxa de crescimento esperada do produto $g_{i}^{e}=\frac{Y_{t}^{e}-Y_{t-1}}{Y_{t-1}}$, então a equação do investimento acima pode ser reescrita como,

$$
I_{t}=\eta_{0} Y_{t-1}+\eta_{1} g_{t}^{e} Y_{t-1}+\eta_{2}\left(\frac{1}{P_{t}}\right) C F_{t}^{e}
$$

Diferente do fluxo de caixa nominal esperado no período $t$ apresentado por Fazzari-Ferri-Greenberg (2003), aqui $C F_{t}^{e}$ é a diferença entre receita nominal esperada $\left(P_{t}^{e} Y_{t}^{e}\right)$ e custos envolvendo o salário nominal esperado $\left(W_{t}^{e}\right)$ e juros nominais predeterminados $\left(R_{t}\right)$ que incidem sobre o estoque nominal da dívida pendente no início do período $t\left(D_{t}\right)$, ou seja,

$$
C F_{t}^{e}=P_{t}^{e} Y_{t}^{e}-W_{t}^{e}-R_{t} D_{t}
$$

Assumindo uma participação constante $(w)^{4}$ do salário nominal na renda nominal agregada esperada, então $W_{t}^{e}=w P_{t}^{e} Y_{t}^{e}$. Assim, a equação (2) pode ser reescrita como,

$$
C F_{t}^{e}=(1-w) P_{t}^{e} Y_{t}^{e}-R_{t} D_{t}
$$

Substituindo (2') em (1'), a função do investimento torna-se

$$
I_{t}=\eta_{0} Y_{t-1}+\eta_{1} g_{t}^{e} Y_{t-1}+\eta_{2}(1-w) Y_{t}^{e}\left(\frac{P_{t}^{e}}{P_{t}}\right)-\eta_{2} R_{t}\left(\frac{D_{t}}{T_{t}}\right)
$$

Com intuito de determinar, mais à frente, a taxa de crescimento atual da economia, $g_{t}=\frac{Y_{t}}{Y_{t-1}}-1$, será obtida a equação do investimento em sua forma intensiva, para isso a equação (3) será dividida por $Y_{t-1}$, ficando

$$
i_{t}=\frac{I_{t}}{Y_{t-1}}=\eta_{0}+\eta_{1} g_{t}^{e}+\eta_{2}(1-w)\left(1+g_{t}^{e}\right)\left(\frac{P_{t}^{e}}{P_{t}}\right)-\eta_{2} \frac{R_{t} D_{t}}{P_{t} Y_{t-1}}
$$

Definindo $d_{t}$ como a razão entre a dívida nominal de início de período $\left(D_{t}\right)$ e a renda nominal defasada $\left(P_{t-1} Y_{t-1}\right)$, ou seja, $\frac{D_{t}}{P_{t-1} Y_{t-1}}$, a equação (4) pode ser reescrita quando no último termo é feita a substituição por $D_{t}$, ficando

$$
i_{t}=\eta_{0}+\eta_{1} g_{t}^{e}+\eta_{2}(1-w)\left(1+g_{t}^{e}\right)\left(\frac{P_{t}^{e}}{P_{t}}\right)-\eta_{2} R_{t} d_{t}\left(\frac{P_{t-1}}{P_{t}}\right)
$$

\footnotetext{
${ }^{3}$ Como sugere o trabalho de Fazzari-Ferri-Greenberg (2003: 5): “Greater cash flow raises the amount of investments that firms can undertake without incurring the risks and costs associated with debt or new share issues".

${ }^{4}$ De fato, os trabalhadores buscam ou aumentar ou manter a participação dos seus salários sobre a renda da economia. Assumindo que, no mínimo, consigam manter suas participações em todos os períodos, então vale que $W_{t}=w P_{t} Y_{t}$, sendo, $0<w<1$.
} 
Pelo fato de,

$$
\pi_{t}=\frac{P_{t}-P_{t-1}}{P_{t-1}} \text { e } \pi_{t}^{e}=\frac{P_{t}^{e}-P_{t-1}}{P_{t-1}} \text {, então, } \frac{P_{t-1}}{P_{t}}=\frac{1}{1+\pi_{t}} \text {, e; } \frac{P_{t}^{e}}{P_{t}}=\frac{\left(1+\pi_{t}^{e}\right)}{\left(1+\pi_{t}\right)}
$$

A equação do investimento em sua forma intensiva fica

$$
\begin{aligned}
& i_{t}=\eta_{0}+\eta_{1} g_{t}^{e}+\eta_{2}(1-w)\left(1+g_{t}^{e}\right) \frac{\left(1+\pi_{t}^{e}\right)}{\left(1+\pi_{t}\right)}-\eta_{2}\left(\frac{R_{t} D_{t}}{\left(1+\pi_{t}\right)}\right) \\
& i_{t}=\eta_{0}+\eta_{1} g_{t}^{e}+\eta_{2} \frac{1}{\left(1+\pi_{t}\right)}\left[(1-w)\left(1+g_{t}^{e}\right)\left(1+\pi_{t}^{e}\right)-R_{t} d_{t}\right]
\end{aligned}
$$

Fazendo $(1-w)=\mu$, obtém-se

$$
i_{t}=\eta_{0}+g_{t}^{e}\left[\eta_{1}+\eta_{2} \mu \frac{\left(1+\pi_{t}^{e}\right)}{\left(1+\pi_{t}\right)}\right]+\frac{\eta_{2}}{\left(1+\pi_{t}\right)}\left[\mu\left(1+\pi_{t}^{e}\right)-R_{t} d_{t}\right]
$$

A equação (5B), além de capturar elementos fundamentais da teoria do investimento de Minsky (2004), tais como, (i) o efeito acelerador (por meio do termo de crescimento, $\left.g_{t}^{e}\right)$, (ii) o efeito da distribuição de renda sobre o investimento por meio da participação do salário no fluxo de caixa, e (iii) a restrição dos investimentos correntes devido à necessidade de servir a dívida contratual, ou seja, o estoque acumulado de dívidas de financiamentos de atividades passadas afetando o investimento corrente, é argumentada, também, pela influência que exercem as expectativas formadas para a inflação sobre o investimento.

\section{Consumo}

A função consumo apresentada possui relação com os pressupostos sugeridos por Keynes acerca de seu comportamento explicado pela renda; contudo, no presente trabalho, encontra-se argumentada pelas expectativas formadas para a renda e levando em consideração as influências do efeito riqueza e da participação dos trabalhadores na renda. De acordo com Keynes (1982: 84): "O montante que a comunidade gasta em consumo depende, evidentemente: (i) em parte, do montante de sua renda; (ii) em parte, de outras circunstâncias objetivas que o acompanham; e (iii) em parte, das necessidades subjetivas, propensões psicológicas e hábitos dos indivíduos que a compõem, bem como dos princípios que governam a distribuição da renda entre eles (que são passíveis de modificações à medida que aumenta a produção)".

A importância que Keynes (1982: 94-95) confere ao comportamento do consumo como um elemento a influir na formação das expectativas e, por conseguinte, sobre a decisão de investir, por meio de sua influência sobre a demanda esperada, pode ser identificada por meio de três passagens: 1) "O consumo - para repetir o óbvio - é o único fim e objetivo da atividade econômica. As oportunidades de emprego estão necessariamente limitadas pela extensão da procura agregada. A demanda agregada só pode ser derivada do consumo presente ou das reservas para 
o consumo futuro"; 2) "Os novos investimentos de capital só podem realizar-se em excesso ao desinvestimento atual do capital quando se espera um aumento dos gastos futuros em consumo"; e 3) “... cada enfraquecimento na propensão a consumir, considerada como hábito permanente, leva a demanda de capital a enfraquecer-se juntamente com a demanda de consumo".

Diferentemente da função consumo apresentada por Fazzari-Ferri-Greenberg (2003), ${ }^{5}$ a função consumo aqui proposta, expressa pela equação (6), é argumentada por dois termos: o primeiro termo refere-se ao montante que será consumido do ganho sobre a renda do período anterior que não foi consumida, mas sim aplicada, e o segundo termo refere-se ao montante da renda agregada atual que é repassada ao consumo atual por meio da propensão marginal a consumir. $\mathrm{Na}$ equação (6), enquanto $C_{0}$ representa a propensão a consumir da renda que não foi consumida no período anterior e que foi aplicada, gerando um aumento de riqueza, $C_{1}$ representa a propensão a consumir da renda atual.

$$
C_{t}+C_{0}\left(R_{t}\right)\left(1-C_{1}\right)\left(Y_{t-1}\right)+C_{1}\left(Y_{t}\right) \text {, em que, } 0<\mathrm{C}_{0} \text { e } \mathrm{C}_{1}<1
$$

\section{Determinação do produto}

O equilíbrio no mercado do produto é obtido por meio da igualdade entre oferta e demanda, sendo o produto $\left(Y_{t}\right)$ determinado pela demanda $\left(D D_{t}\right)$, em que a equação da demanda é dada por

$$
D D_{t}=C_{t}+I_{t}
$$

Logo, o equilíbrio ocorre quando

$$
Y_{t}=C_{t}+I_{t}
$$

Expressando a equação (6) na equação (8) e dividindo a equação (8) pelo produto defasado em um período com intuito de obter o produto em sua forma intensiva, determinando, assim, a taxa de crescimento atual do produto da economia, obtém-se

$$
1+g_{t}=\frac{Y_{t}}{Y_{t-1}}=i_{t}+C_{0}\left(R_{t}\right)\left(1-C_{1}\right)+\frac{C_{1}\left(Y_{t}\right)}{Y_{t-1}}
$$

Logo,

$$
1+g_{t}=\frac{Y_{t}}{Y_{t-1}}=\left(\frac{1}{1-C_{1}}\right)\left[i_{t}+C_{0}\left(R_{t}\right)\left(1-C_{1}\right)\right]
$$

\footnotetext{
${ }^{5}$ A função por eles apresentada consiste do seguinte: $C_{t}=\lambda_{1}\left(1+g_{t}^{e}\right) Y_{t-1}+\lambda_{2} Y_{t-1}$. Nas palavras de FazzariFerri-Greenberg (2003: 7): "We specify consumption with a combination of forward-looking and 'rule of thumb' behavior". E explicam: "Some consumers forecast period $t$ income with an expected growth rate. The coefficient $\lambda_{1}$ combines the share of forward-looking consumers with their marginal propensity to consume. Other consumers base their period $t$ consumption on period $t-1$ income as reflected by the second term in the consumption function. The share of these consumers times their marginal propensity to consume is $\lambda_{2}$ ”.
} 
Substituindo o investimento, equação (5B), na equação (9A) e fazendo o termo multiplicador $\left(\frac{1}{1-C_{1}}\right)=\kappa$ e $\left(1-C_{1}\right)=\gamma$, a equação (9B) obtida abaixo descreve um modelo multiplicador-acelerador.

$$
\frac{Y_{t}}{Y_{t-1}}=k\left[\eta_{0}+g_{t}^{e}\left[\eta_{1}+\eta_{2} \mu \frac{\left(1+\pi_{t}^{e}\right)}{\left(1+\pi_{t}\right)}\right]+\frac{\eta_{2}}{\left(1+\pi_{1}\right)}\left[\mu\left(1+\pi_{t}^{e}\right)-R_{t} d_{t}\right]+C_{0}\left(R_{t}\right)(\gamma)\right]
$$

\section{O “TRINÔMIO” E SUA INFLUÊNCIA SOBRE O DESEMPENHO ECONÔMICO}

A presente seção trata de apresentar a influência da reputação, da credibilidade e da transparência da autoridade monetária e suas políticas (doravante chamado de trinômio) sobre o estado de expectativas para a inflação e a inflação em si, e também para as expectativas formadas para o crescimento econômico. Será visto que a influência sobre a inflação acaba, em última instância, afetando o comportamento do produto e da renda, pois tanto a força reputacional da autoridade monetária quanto seu tipo de reputação, assim como a transparência ${ }^{6} \mathrm{com}$ que atua, exercem um papel de destaque sobre as expectativas formadas pelos agentes econômicos. Quanto à força reputacional que possui a autoridade monetária, Blinder (1999: 44), em contraposição à hipótese Barro-Gordon, de que a reputação seja zero ou 1 , sugere que essa admite diferentes gradações: "There are many types of central banker, not just two, and random shocks cloud the mapping from outcomes back to types. For these and other reasons, reputation is not like pregnancy: You can have either a little or a lot". O trabalho reconhece que a força reputacional da autoridade monetária possa aumentar e diminuir, possuindo assim diferentes graus; entretanto, com intuito de elaborar uma análise acerca da influência desse elemento sobre o desempenho econômico, analisa dois casos distintos - um de reputação consolidada (forte) e outro de fraca reputação (ou em fase de desenvolvimento).

O trabalho, embora aborde a influência do trinômio reputação-credibilidadetransparência da autoridade monetária e suas políticas sobre uma economia operando sob o regime de metas de inflação, confere uma análise mais detalhada ao papel e importância da reputação.

A reputação da autoridade monetária pode ser entendida como a percepção que o público possui a respeito das preferências dessa instituição e da maneira como irá atuar. Essa percepção foi construída fundamentalmente com base em

\footnotetext{
${ }^{6}$ Segundo Woodford (2005: 4): “The ability of central banks to influence expenditures, and hence pricing, decisions is critically dependent upon their ability to influence market expectations regarding the future path of overnight interest rates, and not merely their current level. Better information on the part of market participants about central-bank policy decisions can actually affect these expectations, and so increase the effectiveness of monetary stabilization policy. [...] the public's understanding, not only of what the central bank is currently doing, but of what it can be expected to do in the future, is critical for the effectiveness of policy".
} 
suas ações e seus anúncios e pode se consolidar (fortalecer) ou enfraquecer com o tempo, de acordo com as ações que vão sendo tomadas e os resultados que se observam na economia. Ou seja, a reputação é conquistada a partir dos resultados da política monetária aplicada, não podendo ser determinada por decreto, ou pela simples escolha de alguém que tenha uma tradição antiinflacionária extrema como sugerido por Rogoff (1985). Ao abordar a influência da reputação da autoridade monetária sobre as expectativas e confiança dos agentes econômicos e, assim, sobre o desempenho da economia, o trabalho realiza a análise de dois aspectos distintos acerca da reputação: 1) sua força, isto é, o grau de reputação (que pode se acumular ou se destruir com o tempo), analisando dois casos qualitativos diferentes, quais sejam, se a reputação é fraca (ou ainda em desenvolvimento) ou consolidada (forte); e 2) seu tipo, ou seja, se a autoridade monetária possui a reputação de ser uma instituição que se preocupa somente com a questão da inflação, ou se possui a reputação de ser uma instituição que se preocupa não somente com a inflação, mas também com o lado real da economia.

Ao fazer a distinção a respeito do tipo de reputação da autoridade monetária, isto é, reputação do tipo I - quando a autoridade monetária atua conforme a hipótese de não-neutralidade da moeda, isto é, preocupada com a inflação e com os resultados que se observam em termos de crescimento, emprego e estabilidade do sistema monetário-financeiro - e reputação do tipo II — quando a autoridade monetária atua baseada na hipótese de neutralidade da moeda, se preocupando única e exclusivamente com a questão da estabilidade da inflação -, o trabalho amplia a possibilidade de analisar diferentes implicações da percepção do público acerca da condução da política monetária sobre a economia pelo canal das expectativas.

Primeiramente, serão analisadas duas situações distintas em particular: a primeira - denominada de trinômio tipo I — quando a autoridade monetária possui uma reputação consolidada, atua de maneira transparente e implementa políticas críveis, resultando, assim, na capacidade de fazer convergir tanto as expectativas de inflação quanto a própria inflação para a meta, ou seja, $\pi_{t}^{*}=\pi_{t}=\lambda \pi_{t}^{e}$, em que $\lambda=1$; a segunda — denominada trinômio tipo II — quando a autoridade monetária possui uma reputação fraca, atua de forma opaca (baixa transparência) e implementa políticas não-críveis, resultando em uma situação em que a autoridade monetária encontra dificuldades em fazer convergir a inflação e as expectativas para a inflação para a meta. Nesse segundo caso, a meta de inflação não mais representa o principal referencial de orientação dos agentes para o processo de formação das expectativas de inflação, ou seja, a autoridade monetária não consegue fazer com que os agentes se utilizem da meta de inflação como principal elemento de referência no processo de formação das expectativas. ${ }^{7}$ Isso se deve ao fato do fraco estado de confiança dos agentes na capacidade da auto-

\footnotetext{
${ }^{7} \mathrm{O}$ trabalho não tem como objetivo apresentar nem propor regras alternativas de formação das expectativas dos agentes. Simplesmente argumenta que, em uma situação na qual a autoridade monetária possui baixa reputação, não atua de forma transparente e não implementa políticas críveis (trinômio
} 
ridade monetária fazer convergir as expectativas de inflação para a meta. Assume-se para a situação do tipo II que $\pi_{t}=\lambda \pi_{t}^{e}$, sendo $\lambda>1$. Os resultados sugerem que, em uma situação com trinômio tipo I, a trajetória do produto apresenta comportamento preferível àquele apresentado por uma situação com trinômio tipo II. Mais ainda, em uma situação do trinômio tipo I, a autoridade monetária se encontra com mais graus de liberdade para atuar regulando as pressões de liquidez existentes na economia, o que por sua vez afetaria a preferência pela liquidez e, assim, o produto, o emprego e a renda.

Posteriormente, será realizada uma análise acerca do tipo de reputação que a autoridade monetária busca formar, ou seja, se compatível com a hipótese de não-neutralidade da moeda (Reputação do tipo I) ou se compatível com o pensamento tradicional (mainstream) baseado na hipótese de neutralidade da moeda (Reputação do tipo II).

\section{Trinômio tipo I e suas implicações}

Considerando uma autoridade monetária com elevada reputação, atuando de maneira transparente e implementando políticas críveis no tocante a fazer com que tanto a taxa de inflação quanto as expectativas para a taxa de inflação convirjam para uma meta preestabelecida $\pi_{t}^{*}$, então, logrará êxito se fizer com que $\pi_{t}^{e}=\pi_{t}=\pi_{t}^{*}$. Portanto, em um contexto de estabilidade para a taxa de inflação em que tanto as expectativas para a inflação quanto a inflação convergem para a meta de inflação, a equação (11B) pode ser reescrita da seguinte maneira: ${ }^{8}$

$$
\frac{Y_{t}}{Y_{t-1}}=k\left[\eta_{0}+g_{t}^{e}\left(\eta_{1}+\eta_{2} \mu\right)+\eta_{2} \mu-\frac{\eta_{2}}{\left(1+\pi_{t}^{*}\right)}\left(R_{t} D_{t}\right)+C_{0}\left(R_{t}\right)(y)\right]
$$

tipo II), a utilização do regime de metas de inflação não atinge o objetivo de servir como um referencial no processo de formação das expectativas dos agentes para a inflação.

${ }^{8}$ Em um contexto de estabilidade dos preços, os agentes econômicos passam a se preocupar com outras decisões estratégicas que possam afetar os seus negócios; segundo Greenspan (1996): "Price stability obtains when economic agents no longer take account of the prospective change in the general price level in their economic decisionmaking". Blinder (1995) apresenta definição similar: "The definition I've long used for price stability is a situation where ordinary people in their ordinary course of business are not thinking and worrying about inflation". Meltzer (1997), por sua vez, define estabilidade de preços da seguinte forma: "An inflation rate so close to zero that it ceases to be a significant factor in long-term planning". A estabilidade dos preços deve ser entendida como um conceito muito mais amplo, que vai além de uma simples taxa baixa e estável de inflação, mas como um estado marcado por expectativas baixas e estáveis de inflação, em que a incerteza inflacionária é reduzida. O presente trabalho não tem como objetivo analisar os determinantes do processo inflacionário, contudo admite que flutuações do produto só irão se materializar em inflação de demanda caso a utilização da capacidade instalada tenha atingido um nível que torne legítima uma elevação generalizada dos preços. Os empresários se valem da seguinte lógica: sabendo que a autoridade monetária atuará de forma a manter a inflação e as expectativas para a inflação convergindo para a meta, pressões de demanda somente causarão desvios para cima da inflação e das expectativas em relação à meta caso seja baixo o nível de capacidade ociosa; caso contrário, empresários não irão alterar preços, pois, além de saberem que a autoridade monetária atuará de forma austera, dependendo da estrutura competitiva que estejam inseridos podem perder competitividade com a elevação dos seus preços. 
Fazendo: $\Omega=\eta_{0}+\eta_{2} \mu, \mathrm{A}=\eta_{1}+\eta_{2} \mu, Z=C_{0} \gamma$ e $\Phi=\frac{\eta_{2}}{\left(1+\pi_{t}^{*}\right)}$, então,

$$
\frac{Y_{t}}{Y_{t-1}}=k\left[\Omega+A g_{t}^{e}+R_{t}\left(Z-\Phi d_{t}\right)\right]
$$

A equação (12B) mostra um comportamento para a evolução do produto e da renda compatível com o princípio da demanda efetiva, em que produto e emprego são determinados pelas expectativas de demanda formadas pelos agentes econômicos, o que em última instância acaba por afetar as expectativas de crescimento do produto e, assim, a própria trajetória de crescimento do produto. Observa-se que em uma situação do tipo I em que a estabilidade inflacionária é alcançada, os agentes passam a desconsiderar a influência da inflação e das expectativas para a inflação sobre os seus negócios, pois acreditam que a autoridade monetária logrará êxito em atingir sua meta estabelecida para a inflação. Sendo assim, a evolução do produto/renda no tempo passa a ser uma função da taxa de crescimento esperada do produto $\left(g_{t}^{e}\right)$, da taxa de juros nominal de mercado $\left(R_{t}\right)$ e da razão entre o estoque da dívida nominal de início de período e a renda nominal defasada, $\left(d_{t}\right)$. Se um maior crescimento do produto é esperado, os investimentos se elevam, o que envolverá maior utilização de fatores de produção no processo produtivo, levando, portanto, a um crescimento da renda na economia. A expectativa de aumento da demanda estimula o investimento, que junto com o aumento do consumo e por meio do efeito multiplicador elevam o nível do produto. Quanto à influência da taxa de juros $\left(R_{t}\right)$ sobre o crescimento do produto, essa exerce um efeito ambíguo que pode ser assim explicado: se a taxa de juros aumentar, existirão dois efeitos atuando, em direções opostas, sobre a trajetória de crescimento do produto; o primeiro está relacionado ao efeito riqueza dos indivíduos, que estimulará o consumo e assim o produto e a renda, o segundo relacionado ao custo de servir a dívida contraída pelas firmas, reduzindo o fluxo de caixa nominal esperado e, assim, os investimentos e, conseqüentemente, o produto e a renda.

De acordo com o modelo, um ambiente com inflação baixa e estável é fundamental para o alongamento do horizonte de planejamento das firmas, incluindo aí previsões relacionadas aos recebimentos e dispêndios esperados pelos empresários. Fica evidente que um mecanismo sincronizado de formação de preços e salários beneficia as decisões de investimento na economia.

\section{Trinômio tipo II e suas implicações}

Em uma situação do tipo II, dado que a autoridade monetária encontra dificuldades em fazer com que a inflação e as expectativas para a inflação convirjam para a meta preestabelecida e, além disso, a própria meta de inflação deixa de servir como um referencial de formação das expectativas, com base na equação (11B), resultados adversos podem ser observados.

Uma situação do tipo II, na qual a inflação observada em $t$ é maior que a expectativa de inflação para $t$ formada em $t-1$, ou seja, $\pi_{t}>\pi_{t}^{e}, \operatorname{com} \lambda>1$, pode ser 
justificada por meio do seguinte argumento: na tentativa de neutralizar eventuais perdas de participação no produto que possam ocorrer devido a um aumento generalizado dos preços, os agentes econômicos buscam formar preços acima das expectativas formadas para a inflação. Assim, no que os agentes, de forma generalizada, formam preços acima das expectativas de inflação com o intuito de manterem ou até mesmo aumentarem suas participações no produto da economia, o relativo de preço formado, que resultará na inflação observada, apresentará um resultado superior ao resultado que se verifica para a inflação esperada. ${ }^{9}$

Sendo assim, com base na equação (11B) que descreve a trajetória de crescimento do produto, os seguintes resultados podem ser extraídos:

- Com relação ao termo que explica a influência do crescimento esperado do produto $\left(g_{t}^{e}\right)$ sobre a trajetória de crescimento do produto, numa situação do tipo II com expectativas de inflação se elevando, verifica-se que $\mathrm{A}>\eta_{1}+\eta_{2} \mu \frac{\left(1+\pi_{i}^{c}\right)}{(1+\pi)}$. Isso implica que caso seja observado um aumento nas expectativas de crescimento para o produto, a situação do tipo II apresentará uma trajetória de crescimento do produto menor do que aquela verificada em uma situação do tipo I. Assim, resultados piores em termos de produto, emprego, renda e inflação são verificados quando a autoridade monetária possui baixa reputação, não atua de forma transparente e não implementa políticas críveis.

- O termo independente $\eta_{0}+\eta_{2} \mu \frac{\left(1+\pi_{t}^{e}\right)}{\left(1+\pi_{t}\right)}$ também leva a trajetória de crescimento do produto a apresentar resultados piores quando comparada à situação do tipo I, pois, $\eta_{0}+\eta_{2} \mu\left(\frac{\left(1+\pi_{t}^{*}\right)}{\left(1+\pi_{t}\right)}<\eta_{0}+\eta_{2} \mu\right.$.

- O termo $\left[\frac{\eta_{2}}{\left(1+\pi_{)}\right)}\right]\left(-R_{,}, d_{1}\right)$ também faz com que a trajetória de crescimento do produto seja inferior à situação do tipo I. Em uma situação do tipo II, caso a inflação esteja dando sinais de estar se desviando do objetivo estabelecido, a autoridade monetária terá maior dificuldade em trazer a inflação para próximo da meta, necessitando ajustar o instrumento de política monetária (taxa de juros) de maneira mais abrupta, ou seja, promovendo maior elevação da taxa de juros e com isso acarretando um custo maior para a sociedade. No que a taxa básica de juros se eleva, aumentam as demais taxas de juros nominais de mercado, desestimulando os investimentos, pois, além das aplicações financeiras ficarem mais atrativas (desviando recursos

\footnotetext{
${ }^{9}$ Tal hipótese tem como referência os argumentos apresentados por Kandir (1989: 84), que por sua vez se inspira em Frenkel (1979). De acordo com o primeiro, “ocorrendo um choque inflacionário na economia, os agentes produtivos em todos os segmentos passam a esperar um aumento na variação de seus custos. Em conseqüência procuram aumentar preventivamente seus mark-ups. Mas de que magnitude? Se errarem para baixo perderão pelo aperto das margens. Se errarem para cima, perderão pela diminuição das quantidades vendidas. Trata-se de uma escolha sob risco. Frenkel mostrou que um processo racional de decisão conclui por um viés no sentido de evitar-se o erro de subestimar a evolução dos custos. Assim, quando ocorrem choques inflacionários, surge um elemento acelerador que corresponde ao viés de superestimar as expectativas de evolução dos custos”.
} 
da esfera real), o custo de financiar os projetos de investimento se eleva, aumentando também o estoque da dívida contraída que se acumula.

\section{Implicações do tipo de reputação sobre a economia}

Para o desenvolvimento dessa análise, chamaremos de Reputação do tipo I a autoridade monetária que atua conforme a hipótese de não-neutralidade da moeda - sendo a política monetária capaz de afetar tanto o lado nominal quanto o lado real da economia -, e Reputação do tipo II a autoridade monetária que atua conforme a hipótese de neutralidade da moeda — sendo a política monetária implementada com o intuito de controlar a taxa de inflação conforme uma regra de manipulação da taxa de juros, não importando a origem do processo inflacionário. Além da implementação desses novos aspectos na análise, será introduzida uma equação para o comportamento das expectativas formadas para o produto.

A equação irá mostrar que as expectativas formadas para o produto são explicadas como uma função da taxa de inflação por meio do seguinte trade-off: quando a inflação aumenta, espera-se que o produto se reduza e vice-versa. Argumenta-se, dessa maneira, por uma relação inversa entre inflação $(\pi)$ e expectativas formadas para o produto ( $\left.Y^{e}\right)$, expressa pela equação (13), em que $\Omega$ simboliza um parâmetro autônomo representativo de todas as demais variáveis que afetam $\left(Y^{e}\right)$ e que, no entanto, foram omitidas do modelo, e o parâmetro $(\lambda)$ da equação capta a influência da reputação da autoridade monetária sobre as expectativas formadas para o produto $\left(Y^{e}\right)$ quando são verificadas alterações na taxa de inflação $(\pi)$.

$$
Y^{e}=\Omega-\lambda . \pi
$$

A equação (13) mostra que as expectativas formadas para o produto são inversamente relacionadas à taxa de inflação devido à percepção dos agentes quanto às políticas econômicas que serão utilizadas para conter o processo inflacionário, assim como devido à percepção dos agentes acerca do comprometimento dos policymakers com seus objetivos. Ou seja, os agentes esperam, por exemplo, que sejam implementadas políticas econômicas que inevitavelmente levarão a uma redução do produto demandado e/ou da renda, quando a inflação se elevar - e vice-versa. Nesse sentido, pode ser estabelecida a existência de uma relação entre a reputação da autoridade monetária e o parâmetro $(\lambda$.) e, assim, sobre o desempenho da economia por meio das expectativas.

Espera-se, por exemplo, que quanto maior for a importância atribuída aos resultados observados para o produto, pela autoridade monetária - possuindo, portanto, a reputação de ser uma instituição preocupada com os resultados que se observam sobre o lado real da economia, buscando, assim, melhorar o desempenho em termos de produto e renda -, menor será a influência da inflação sobre as expectativas formadas para o produto do período seguinte, indicando, nesse sentido, um parâmetro $(\lambda$.) com um baixo valor. Portanto, ao se verificar uma alteração na taxa de inflação, essa não trará como conseqüência um impacto adverso 
tão forte sobre o produto da economia quanto aquele que seria observado caso a autoridade monetária possuísse a reputação de ser uma instituição preocupada única e exclusivamente com a inflação.

Nesse sentido, as alterações no produto podem ser analisadas com base na seguinte hipótese acerca da influência da reputação da autoridade monetária sobre o desempenho da economia: as variações nas expectativas formadas para o produto, explicadas por variações na inflação, são maiores quando a reputação da autoridade monetária for do tipo $I I$, e as variações nas expectativas formadas para o produto, explicadas por variações na inflação, serão menores quando a reputação da autoridade monetária for do tipo $I$, o que equivale à $\hat{\lambda}_{\text {tipolI }}>\lambda_{\text {tipol }}$.

Para o caso de uma taxa de inflação se elevando e acelerando, os resultados, em termos de variação no produto, mostram que é melhor a autoridade monetária possuir uma Reputação do tipo I do que uma Reputação do tipo II. Pelo fato de $\lambda_{\text {tipolI }}>\lambda_{\text {tipol }}$, então, mesmo se a autoridade monetária não buscasse controlar o aumento na variação da taxa de inflação pela manipulação da taxa de juros, o resultado, em termos de variação do produto, seria pior, para o caso de uma autoridade monetária com Reputação do tipo II, pois geraria um estado de expectativas pessimistas em relação ao comportamento do produto no futuro, devido, justamente, à reputação ostentada pela autoridade monetária.

Para o caso de uma inflação de custos, o melhor que a autoridade monetária faz (em termos de resultados para o produto) é possuir uma reputação do tipo I e não combater a inflação pela elevação da taxa de juros, pois: 1) a aceleração da inflação trará uma redução maior sobre o produto, caso a reputação da autoridade monetária seja do tipo II, dado que $\lambda_{\text {tipolI }}>\lambda_{\text {tipol }}$; e 2) pelo fato da autoridade monetária reagir aumentando a taxa de juros, isso faz com que o produto se reduza mais ainda, já que uma taxa de juros mais elevada implica um custo financeiro maior (como será melhor detalhado na seção seguinte). Além disso, como argumenta Palacio-Vera (2005: 763): “A policy reaction function like the one used by Romer (2000) or any variant of the policy rule proposed by Taylor (1993) is an inadequate way of coping with an adverse SS [supply shock]".

A reputação que a autoridade monetária constrói e busca fortalecer com o tempo (por meio do "fazer aquilo que anuncia e sinaliza" de acordo com seus objetivos e seu alcance) se caracteriza como um elemento determinante para o processo de tomada de decisões dos agentes que operam em uma economia. Pois, ao estabelecer certa reputação, a autoridade monetária induz os agentes econômicos a tomarem decisões conforme as expectativas que formam acerca de sua reação. Nesse sentido, sua reputação torna-se fundamental para o conhecimento dos agentes acerca do modo como a autoridade monetária enxerga o funcionamento da economia e do modo como reage aos distúrbios que nela ocorrem.

Ao reconhecer que suas políticas são capazes de afetar tanto a esfera nominal quanto a esfera real e, dessa maneira, assumir uma postura compatível com a sua capacidade de promover a estabilização tanto dos preços quanto do produto, 
atuando por meio de políticas coordenadas com as demais políticas econômicas, cria a reputação de ser uma instituição não somente preocupada em controlar a inflação, mas a reputação de ser uma instituição que atua de acordo com as necessidades levantadas pela sociedade, quer sejam associadas com o lado real ou o lado nominal da economia.

A autoridade monetária, ao sustentar uma reputação baseada no princípio da neutralidade da moeda, implementando sua política monetária com base em uma regra de elevações da taxa de juros para conter as pressões inflacionárias somente estrangula o crescimento econômico. $\mathrm{O}$ uso da taxa de juros, como forma de combater o processo inflacionário, deve ser parcimonioso e estar de acordo com o diagnóstico preciso de inflação.

\section{DINÂMICA DA DÍVIDA}

Em um arcabouço pós-keynesiano, o mercado financeiro e as condições de financiamento que a firma encontra desempenham papéis centrais na determinação da trajetória de crescimento do produto e do emprego na economia. De acordo com Fazzari e Variato (1994: 355): "The ability of a firm to undertake an investment project may depend not only on the fundamentals of the project under consideration, but also on the firm's financial condition. Projects in which firms would invest if they had sufficient internal funds might not be undertaken if the firm must raise external funds to finance the project". Nesse sentido, o estoque da dívida possuída pelas firmas pode representar uma restrição para a obtenção de crédito necessário para a implementação de projetos de investimento.

Com o intuito de tornar o comportamento do investimento dinâmico, abordando a influência da postura financeira assumida pela firma sobre o seu investimento, e também a influência que exerce a autoridade monetária, por meio de manipulações da taxa de juros sobre a dívida, o modelo pode ser expandido de modo a apresentar a equação que explica o processo dinâmico de endividamento da firma.

A dívida no início do período $t$ é igual à dívida no início do período $t$-1, mais a taxa de juros nominal em $t$ - 1 que incide sobre a dívida do mesmo período, mais o investimento nominal realizado no período anterior $\left(P_{t-1} I_{t-1}\right)$, e menos o fluxo de caixa nominal no período $t-1$, ou seja,

$$
D_{t}=D_{t-1}\left(1+R_{t-1}\right)+P_{t-1} I_{t-1}-C F_{t-1}
$$

Dividindo a equação de acumulação da dívida pela renda nominal defasada, obtém-se

$$
d_{t}=\frac{D_{1}}{P_{t-1} Y_{t-1}}=\frac{D_{t-1}\left(1+R_{t-1}\right)+P_{t-1} I_{t-1}-\left[(1-w) P_{t-1} Y_{t-1}-R_{t-1} D_{t-1}\right]}{P_{t-1} Y_{t-1}}
$$


Resolvendo, ${ }^{10}$ chega-se a

$$
d_{t}=\left[\frac{\left(1+2 R_{t-1}\right)}{\left(1+g_{t-1}\right)\left(1+\pi_{t-1}\right)}\right] d_{t-1}+\frac{i_{t-1}}{\left(1+g_{t-1}\right)}-(1-w)
$$

A equação (15A) mostra que quando tanto a dívida do período anterior quanto o serviço da dívida do período anterior se alteram, a dívida do período corrente também se altera, ou seja, $\frac{\partial d_{1}}{\partial d_{t-1}}>0$ e $\frac{\partial d_{1}}{\partial R_{t-1}}>0$. Além disso, se ocorrer uma elevação na taxa de crescimento econômico do período anterior, a dívida das firmas irá diminuir, como pode ser visto por $\frac{\partial d_{1}}{\partial g_{t-1}}>0$; e, se a inflação estiver dando sinais de estar se acelerando, então a dívida irá diminuir em termos reais. O segundo termo aponta para o fato de dívida estar se alterando em função de modificações nos gastos com investimentos, ou seja, $\frac{\partial d_{1}}{\partial i_{-1}}>0$. O terceiro termo indica que se a participação dos trabalhadores no produto se altera, então as dívidas das firmas irão se alterar no mesmo sentido.

Considerando uma situação em que prevalece o trinômio do tipo I, o seguinte raciocínio pode ser construído: no que a inflação observada e as expectativas para a inflação convergem para a meta, manipulações na taxa básica de juros com intuito de controlar a inflação tornam-se menos freqüentes; isso se reflete em estabilidade nas taxas de juros nominais de mercado, que, como conseqüência, traz estabilidade para o comportamento da dívida das firmas, instaurando um ambiente em que os planos de investimento podem ser alongados. Embora, por um lado, a dívida das firmas possa estar aumentando por meio da elevação dos investimentos, por outro, dado que ocorre crescimento econômico, essa dívida diminui, pois, no que a renda aumenta, isso se reverte em consumo e conseqüentemente em receita para as firmas, que terão recursos para honrar seus compromissos.

Em uma situação do tipo II entretanto, dada a dificuldade encontrada pela autoridade monetária em fazer tanto a inflação quanto as expectativas para a inflação convergirem para a meta, no que a inflação dá sinais de estar aumentando, a taxa básica de juros será elevada, e, com isso, a dívida das firmas irá aumentar. Se a autoridade monetária vem ao longo do tempo implementando esse tipo de política devido à dificuldade que encontra em fazer a inflação e as expectativas convergirem para a meta, o que se verifica é uma trajetória de deterioração no

$$
\begin{aligned}
& { }^{10} \text { Se } D_{t-1}=d_{t-1} \mathrm{P}_{\mathrm{t}-2} Y_{\mathrm{t}-2}, \operatorname{logo} \text {, substituindo na equação (14), fica } \\
& d_{t}=\frac{d_{t-1} P_{t-2} Y_{t-2}+2 R_{t-1} d_{t-1} P_{t-2} Y_{t-2}}{P_{t-1} Y_{t-1}}+\frac{I_{t-1}}{Y_{t-1}}-(1-w) . \\
& \text { Assim, } d_{t}=\left[\frac{\left(1+2 R_{t-1}\right) P_{t-2} Y_{t-2}}{P_{t-1} Y_{t-1}}\right] d_{t-1}+\frac{I_{t-1}}{Y_{t-1}}-(1-w), \\
& \text { sendo } \frac{I_{t-1}}{Y_{t-1}}=\frac{i_{t-1}}{\left(1+g_{t-1}\right)}, \text { e } \frac{1}{\left(1+g_{t-1}\right)\left(1+\pi_{t-1}\right)}=\frac{p_{t-2} Y_{t-2}}{P_{t-1} Y_{t-1}} \text {, então, substituindo em (14), obtém-se a equação }
\end{aligned}
$$


caixa das firmas por conta do aumento de suas dívidas. Nesse contexto, as dívidas aumentam, os investimentos diminuem, resultando em baixo crescimento econômico, ou até mesmo crescimento nulo ou negativo.

Nesse sentido, como aponta de Carvalho (2005: 334-335): “A política monetária, como as outras políticas de administração de demanda agregada, afeta tanto os níveis de preços quanto o nível de atividade e a taxa de crescimento da economia (ao afetar a decisão de investir). Pelas razões apresentadas, é provável que a política monetária seja mais importante para influenciar o crescimento da economia que a política fiscal. Por isso, uma primeira conclusão importante é a de que a política monetária é uma política de governo, a ser decidida juntamente com as outras políticas de governo". Entende-se com isso que a política monetária não deve ser implementada para atingir um único objetivo e não deve se basear numa regra rígida que desconsidera o funcionamento complexo da economia. Mas, sim, deve ser conduzida de maneira coordenada com as demais políticas econômicas de modo a alcançar os objetivos do governo, que, em última instância, representam os desejos da sociedade.

Quando buscando formar e consolidar sua reputação, a autoridade monetária adota um regime de meta de inflação; contudo, utilizando uma regra de política monetária (manipulação da taxa de juros), conduz a um generalizado "estado de expectativas" pessimista quanto ao comportamento das variáveis reais da economia, pois induz os agentes a elevarem sua preferência pela liquidez. Se esse "estado de expectativas" vem se verificando ao longo do tempo, sustentado pela reputação da autoridade monetária, o que veremos é uma economia em constante estado de semidepressão. É nesse sentido que a reputação da autoridade monetária desempenha um papel fundamental de induzir, quando uma política monetária for implementada, os agentes econômicos a trocarem ativos mais líquidos por ativos de longo prazo, estimulando os investimentos.

O Quadro 1 abaixo ilustra o comportamento dos preços, da taxa de crescimento econômico e da preferência pela liquidez para os casos em que a autoridade monetária possui reputação consolidada ou fraca e, também, elevada ou pouca credibilidade e transparência (trinômio tipo I e II, respectivamente), assim como para os casos de reputação do tipo I e II, compatíveis com as hipóteses de nãoneutralidade e neutralidade da moeda.

Quadro 1: Comportamento dos preços, crescimento e liquidez sob diferentes tipos de política monetária

\begin{tabular}{|c|c|c|c|c|}
\hline \multicolumn{2}{|c|}{$\begin{array}{l}\text { Postura e força da autoridade } \\
\text { monetária }\end{array}$} & $\begin{array}{l}\text { Comportamento } \\
\text { dos preços }\end{array}$ & $\begin{array}{l}\text { Comportamento da } \\
\text { taxa de crescimento }\end{array}$ & $\begin{array}{l}\text { Preferência } \\
\text { pela liquidez }\end{array}$ \\
\hline \multirow{2}{*}{$\begin{array}{l}\text { Reputação con- } \\
\text { solidada, elevada } \\
\text { credibilidade e } \\
\text { transparência } \\
\text { (trinômio tipo I) }\end{array}$} & $\begin{array}{l}\text { Reputação } \\
\text { do tipo I }\end{array}$ & Estabilidade & $\begin{array}{l}\text { Crescimento } \\
\text { sustentável }\end{array}$ & Baixa \\
\hline & $\begin{array}{c}\text { Reputação } \\
\text { do tipo II }\end{array}$ & Estabilidade & $\begin{array}{c}\text { Estagnação ou } \\
\text { recessão }\end{array}$ & Alta \\
\hline
\end{tabular}




\begin{tabular}{|c|c|c|c|c|}
\hline \multirow{2}{*}{$\begin{array}{l}\text { Reputação fraca, } \\
\text { pouca credibilidade } \\
\text { e transparência } \\
\text { (trinômio tipo II) }\end{array}$} & $\begin{array}{c}\text { Reputação } \\
\text { do tipo I }\end{array}$ & Inflação & $\begin{array}{l}\text { Crescimento } \\
\text { intermitente }\end{array}$ & Alta \\
\hline & $\begin{array}{c}\text { Reputação } \\
\text { do tipo II }\end{array}$ & Inflação & $\begin{array}{l}\text { Estagnação ou } \\
\text { recessão }\end{array}$ & Alta \\
\hline
\end{tabular}

\section{CONCLUSÕES}

Com base no que foi apresentado, pode-se dizer que sob o regime de metas inflacionárias, uma vez que a autoridade monetária tenha alcançado uma situação do tipo I tanto para o tipo de reputação quanto para a força do trinômio, então irá desempenhar um papel no sentido de evitar a ocorrência de trajetórias indesejadas para o produto. A autoridade monetária, agindo de forma transparente, implementando políticas críveis e coordenadas com as demais políticas econômicas, pode induzir os agentes a formarem expectativas com base em sua reputação.

O resultado do modelo desenvolvido mostra que no que a estabilidade da inflação é conquistada, ou seja, no que a meta de inflação é alcançada, a política monetária pode voltar-se para a questão do gerenciamento da liquidez com o objetivo de estimular o crédito e, assim, os investimentos. Além disso, políticas econômicas podem ser implementadas com intuito, por exemplo, de estimular a concorrência bancária, fazendo assim com que as taxas de juros de mercado se reduzam e os investimentos sejam estimulados.

Um detalhe importante do modelo é o fato de que quando o ciclo virtuoso se instaura não necessariamente ele se reverte, como alguns poderiam questionar, por meio do processo de retomada da inflação quando a política monetária se torna gradualmente expansionista. Isto é, não necessariamente a inflação e as expectativas irão se desviar da meta na medida em que a taxa básica de juros vai sendo gradativamente reduzida. Isso decorre da característica do modelo em que os custos financeiros se reduzem, por meio de reduções nas taxas de juros, e as firmas ganham margem para promover reduções nos preços. Se a isso for acrescida a questão do estímulo da concorrência nos mercados, quer seja por meio do crescimento econômico, quer seja por meio de políticas econômicas que induzam a isso, um limitador para o processo de retomada da inflação é fortalecido.

Assim, tornando tanto as expectativas para a inflação mais estáveis quanto a própria inflação compatível com a meta, a autoridade monetária ganha graus de liberdade para implementar políticas que estimulem o lado real da economia, auxiliando, por exemplo, na redução de comportamentos indesejáveis dos investimentos, ligados às incertezas inerentes à atividade de investimento em ativo fixo. Nesse sentido, quanto maior a reputação e a transparência da autoridade monetária em manter a inflação baixa e estável, maiores serão as chances de ocorrer uma melhor trajetória de crescimento do produto.

Contudo, também é uma característica do modelo apontar que são as expectativas de crescimento da economia que alimentam positivamente as expectativas 
de crescimento das firmas, e, portanto, suas decisões de investir em ativo fixo. Assim, se a autoridade monetária ainda não possui uma reputação consolidada e busca essa conquista por meio da utilização de uma regra de manipulação da taxa de juros, reduzindo, assim, o potencial de crescimento da economia, pode cair na situação de trinômio do tipo II descrita no modelo e impor um pesado ônus à economia para atingir o objetivo de estabilizar a inflação.

O presente trabalho, portanto, se diferencia da abordagem tradicional acerca tanto dos condicionantes para a implementação do regime de metas de inflação quanto para as implicações que traz o regime sobre a forma de condução da política monetária e sobre os objetivos a serem perseguidos pela autoridade monetária, argumentando que: 1) a implementação do regime por si só não garante a obtenção dos melhores resultados em termos de inflação e produto para a economia; esses, em parte, estão condicionados a reputação da autoridade monetária, a forma transparente com que essa atua e a implementação de políticas econômicas críveis; 2) a política monetária não deve ser conduzida por meio da utilização de um único instrumento (taxa básica de juros) e com intuito somente de alcançar a estabilidade dos preços e das expectativas para a inflação, sob o risco de afetar de forma significa e sistêmica a estrutura de dívida das firmas (e dos bancos), o que implicaria flutuações indesejadas para o produto sem necessariamente trazer os resultados esperados para os preços; nesse sentido, atenção especial deve ser conferida ao processo de formação de preços das firmas e como esse ocorre para as firmas que se encontram operando em diferentes estruturas de mercado.

\section{REFERÊNCIAS BIBLIOGRÁFICAS}

BARRO, R. J.; GORDON, D. B. (1983) A Positive Theory of Monetary Policy in a Natural Rate Model. Journal of Political Economy, vol. 91, n. 41, 1983a.

(1983) Rules, Discretion and Reputation in a Model of Monetary Policy. Journal of Monetary Economics, 12(1), pp. 101-22, 1983b.

BLINDER, A. (1995) “The strategy of monetary policy”. The Region. September, 1995. . (1999) Central Banking in Theory and Practice. MIT Press, 1999.

CARVALHO, F. C. (2005) "Uma contribuição ao debate em torno da eficácia da política monetária e algumas implicações para o caso do Brasil”. Revista de Economia Política, vol. 25, n. 4; outubro-dezembro, 2005.

EICHENER, A. S. (1979) “A post-Keynesian short-period model”. Journal of Post Keynesian Economics, vol.1, n. 4, Summer 1979.

FAZZARI, S.; VARIATO, A. M. (1994) “Asymmetric information and Keynesian theories of investment”. Journal of Post Keynesian Economics, vol. 16, n. 3, Spring 1994.

FAZZARI, S.; FERRI, P.; GREENBERG, E. (2003) "Cash Flow, Investment, and Keynes-Minsky Cycles". Working Paper, September 2003.

FELLNER, W. J. (1976) Towards a Reconstruction of Macroeconomics: Problems of Theory and Policy. American Enterprise Institute, 1976.

. (1979) The Credibility Effect and Rational Expectations: Implications of the Gramlich Study. Brookings Papers on Economic Activity, n. 1, 167-90, Washington 1979.

FRENKEL, R. (1979) “Decisiones de precio en alta inflación”. In: Estúdios Cedes, Buenos Aires, 2(3), 1979. 
GREENSPAN, A. (1996) “Opening remarks”. In: Symposium on achieving price stability. Proceedings of a conference held by the Federal Reserve Bank of Kansas City, August 1996.

KANDIR, A. (1989) A Dinâmica da Inflação. São Paulo, Nobel, 1989.

KEYNES, J. M. (982) A teoria geral do emprego do juro e da moeda. São Paulo, Atlas, 1982.

KYDLAND, F. E.; PRESCOTT, E. C. (1977) Rules Rather than Discretion: the Inconsistency of Optimal Plans. Journal of Political Economic, 1977, vol. 85, n. 3.

MELTZER, T. C. (1995) "Monetary, credit and other transmission mechanism processes: a monetarist perspective". Journal of Economic Perspective 9, 1995.

MENDONÇA, H. F. (2006) "Transparência, condução da política monetária e metas para a inflação". Nova Economia, Belo Horizonte, 16 (1), p. 175-198, jan./abril 2006.

MINSKY, H. P. (2004) Induced investment and business cycles. Edward Elgar Publishing, 2004.

PALACIO-VERA, A. (2005) "The modern View of Macroeconomics: some critical reflections". Cambridge Journal of Economics, 29, September 20005.

ROMER, D. Advanced Macroeconomics. (2001) Second Edition, McGraw-Hill, 2001.

SVENSSON, L. E. O. (1998) "Inflation targeting as a monetary policy rule". NBER Working Paper 6790, November 1998.

WOODFORD, M. (2005) "Central Bank Communication and Policy Effectiveness". NBER Working Paper 11898, December 2005. 